ARTIGO

\title{
EDUCAÇÃO E LUTA DE TRABALHADORES SEM-TERRA COMO EXPRESSÃO DO CONTRADITÓRIO
}

\author{
EDUCATION AND STRUGGLE OF LANDLESS WORKERS AS AN EXPRESSION OF \\ THE CONTRADICTORY
}

EDUCACIÓN Y LUCHA DE LOS TRABAJADORES SIN TIERRA COMO EXPRESIÓN

DE LO CONTRADICTORIO

\author{
Diogo Marques Tafuri \\ Universidade Federal de São Carlos - Brasil
}

\begin{abstract}
Resumo: Neste artigo, propomos compreensões acerca das intencionalidades inerentes à participação pregressa de agricultores/as assentados/as em processos de luta pela reforma agrária no Brasil. Partimos de um posicionamento epistemológico que considera as práticas sociais vivenciadas pelos seres humanos enquanto práxis intersubjetiva, geradora de processos educativos que se projetam no tempoespaço a partir de situações gnosiológicas problematizadoras da realidade social. Por meio da análise fenomenológica de dados obtidos pelas entrevistas realizadas com agricultores/as assentados/as, argumentamos que a prática da luta pela terra por eles empenhada se configurou enquanto expressão dos processos educativos forjados a partir do contraste de suas experiências de roça e êxodo rural.
\end{abstract}

Palavras chave: Luta pela Terra. Processos Educativos. Trabalhadores sem-terra.

\begin{abstract}
In this paper, we propose understandings about the intentions inherent to the past participation of farmers settled in processes of struggle for agrarian reform in Brazil. We start from an epistemological position that considers the social practices experienced by human beings as intersubjective praxis, generating educational processes that are projected in time-space from gnosiological situations that problematize social reality. Through phenomenological analysis of data obtained through interviews with settled farmers, we argue that the practice of the struggle for land committed by them was configured as an expression of the educational processes forged from the contrast of their agriculture experiences and rural exodus.
\end{abstract}

Key words: Educational Processes. Landless Workers. Struggle for Land.

Resumen: En este artículo, proponemos un entendimiento sobre las intenciones inherentes a la participación pasada de los agricultores asentados en los procesos de lucha para la reforma agraria en Brasil. Partimos de una posición epistemológica que considera las prácticas sociales experimentadas por los seres humanos como praxis intersubjetiva, generando procesos educativos que se proyectan en el espacio-tiempo a partir de situaciones gnoseológicas que problematizan la realidad social. A través del análisis fenomenológico de los datos obtenidos por entrevistas realizadas con agricultores asentados, 
sostenemos que la práctica de lucha para la tierra cometida por ellos se configuró como una expresión de los procesos educativos forjados a partir del contraste de sus experiencias agrícolas y éxodo rural.

Palabras clave: Lucha por la Tierra. Procesos Educativos.Trabajadores sin tierra.

\section{Introdução}

Neste artigo, pretendemos nos aproximar das intencionalidades inerentes a participação pregressa de agricultores/as assentados/as em processos de luta pela reforma agrária no Brasil, engendrados historicamente por movimentos sociais campesinos como reação às consequências do pacto de Economia Política forjado entre os anos 1960 e 1990, marcado pela “(...) articulação do grande capital agroindustrial, do sistema de crédito público à agricultura e à agroindústria e da propriedade fundiária, para estruturar uma estratégia econômica e política de modernização conservadora da agricultura" (DELGADO, 2012, p. 91). Argumentamos que a prática da luta pela terra, realizada dentro desta conjuntura por tais trabalhadores, atualmente assentados/as pelo II Plano Nacional da Reforma Agrária, se configurou enquanto expressão dos processos educativos forjados a partir do contraste de suas experiências de roça e êxodo rural, vivenciadas entre a infância e o início da vida adulta.

As possibilidades de implantação, por parte do Estado brasileiro, dos projetos de assentamentos rurais como forma de atender as reivindicações populares de acesso à terra estiveram condicionadas, desde a década de 1960, por uma conjuntura histórica marcada principalmente pelas tensões existentes entre: a) a crescente pressão exercida pelos movimentos sociais decorrente da perenidade da concentração fundiária e do aumento da pobreza e da desigualdade social no campo; b) a atuação estatal no fomento ao desenvolvimento de uma agricultura capitalista integrada à economia urbano-industrial e ao setor externo, tendo como fundamento a modernização na base técnica dos meios de produção agrícolas por meio da qualificação técnica do trabalho rural, do aumento no nível de mecanização da atividade agrícola e da utilização de insumos industriais no manejo produtivo (DELGADO, 1984; 2012). Se, em período anterior, a grande oferta de terras e a possibilidade de expansão gradativa da fronteira agrícola favoreceram as explorações pioneiras e temporárias de posseiros e o aumento do número de pequenos estabelecimentos rurais, a partir dos anos de 1970 esta tendência é revertida, sendo a agricultura nacional marcada pela tendência geral da expansão e incorporação de áreas dedicadas às lavouras comerciais de grande aporte tecnológico em detrimento das áreas tradicionalmente ocupadas pela pequena produção agrícola, caracterizada pela produção de 
gêneros alimentícios voltados à subsistência e ao comércio de excedente (GRAZIANO DA SILVA, 1980).

A modificação da base tecnológica em que se sustentava a produção agrícola brasileira, propiciada pelas políticas macroeconômicas voltadas para o incremento produtivo do setor, ao ampliar a produtividade do trabalho no campo por meio do aumento no nível de mecanização agrícola, alterou sobremaneira a escala de exploração das propriedades rurais, provocando o acréscimo da quantidade das áreas mínimas necessárias para garantia da rentabilidade econômica das atividades agropecuárias. Deste modo, transformou significativamente as características e as formas de absorção do trabalho rural utilizado nos ciclos das principais lavouras, com o notório aumento da sazonalidade e diminuição dos postos de trabalho no setor agropecuário, acarretando a ampliação do excedente de força de trabalho agrícola e a intensificação do êxodo rural que, em grande parte, se direcionou rumo aos grandes e médios centros urbanos. Por outro lado, ao conformar uma estrutura agrária concentrada e excludente, expropriou parte da população camponesa do usufruto da terra de trabalho, aprofundando os níveis de desigualdade social no meio rural e erigindo as possibilidades históricas de envolvimento deste segmento social marginalizado em processos de resistência e disputa pela posse da terra (CARVALHO, 2011; MARTINE, 1991).

Dentro de tal conjuntura, discutiremos as distintas formas de conscientização do contraditório experenciadas, ao longo das trajetórias de vida no campo e na cidade, por agricultores/as viventes em um assentamento rural paulista, argumentando tratar-se, tal ação reflexiva, de elemento significativo para a manifestação da intersubjetividade política construída a partir da ação combativa dos movimentos de trabalhadores sem-terra, tomados enquanto sujeitos coletivos de construção e transformação histórica. As experiências de roça vivenciadas pelos sujeitos rurícolas em suas infâncias e início da vida adulta, sobrepostas àquelas experimentadas no contexto de inserção de suas famílias no meio urbano e da transitoriedade e precariedade dos trabalhos e meios de vida ali obtidos, sedimentaram-se na subjetividade destes sujeitos de modo constitutivo em relação às escolhas e decisões passadas que condicionariam o rumo de suas trajetórias futuras, culminando posteriormente no ingresso em movimentos de luta pela terra e no regresso ao meio rural.

No Brasil, o campo investigativo constituído em torno da temática "educação e movimentos sociais campesinos" tem dado ênfase, de um lado, às condições gerais de ensino/aprendizagem características do processo de consolidação da educação do campo como nova modalidade de educação no cenário nacional (formação de professores e educadores, 
adequação dos currículos, formação multisseriada e a formulação de políticas e programas educacionais), delimitando a esfera da educação formal; de outro, na função educativa dos movimentos sociais e sua relação com processos de conscientização política entre camponeses, demarcando um campo de estudo da educação não-formal (MIRANDA \& FIUZA, 2017; SOUZA, 2020). Dialogando com os trabalhos vinculados a esta última linha de investigação, a despeito da constatação da existência de uma importante produção de conhecimento acerca de como experiência educativa vivenciada em movimentos sociais vem favorecendo a conscientização e emancipação dos sujeitos diante de realidades opressoras, tais pesquisas pouco contribuíram até o presente para a compreensão das condições pregressas (tomadas enquanto experiências educativas) que permitiram a eclosão das ações de resistência e luta camponesa, as quais culminariam no ingresso de parte da população rurícola em movimentos sociais pró reforma agrária.

Ao reconhecer a abrangência e permanência dos processos educativos vivenciados em práticas sociais espaço-temporalmente situadas, bem como seu papel para conformação de formas individuais e coletivas de ser, agir, significar, transformar e transformar-se ao mundo, pudemos problematizar o fenômeno da luta pela terra em relação às condições objetivas, subjetivas e intersubjetivas de constituição e consolidação dos espaços sociais de vida e reprodução da agricultura familiar brasileira (fundamentais que são para a construção da cidadania no campo e para a redução das assimetrias sociais e de poder de nossa sociedade democrática). Destarte, auxiliando na diferenciação entre os distintos contextos históricos que produziram e conformaram, de um lado, o desígnio da luta para viver da terra experienciado pela geração camponesa assentada, e de outro, a intenção atual de seus filhos em quererem ou não permanecer vivendo no campo, este estudo pode fornecer algumas pistas para o entendimento da questão do envelhecimento dos assentamentos de reforma agrária e de seu fenômeno correspondente, a saber, sua sucessão geracional, temáticas que reconhecidamente se constituem enquanto lacuna de conhecimento da produção acadêmica que versa sobre educação e movimentos sociais (SOUZA, 2020).

\section{Compreendendo processos educativos em práticas sociais}

Partimos de um posicionamento epistemológico que afirma a existência de processos educativos em práticas sociais construídas nas relações tecidas entre as pessoas, entre estas e sua comunidade de pertencimento, bem como entre pessoas e grupos, grupos entre si, e nas relações existentes entre tais agrupamentos e o todo social tomado de forma ampla. De acordo 
com Oliveira e colegas, as "[...] práticas sociais decorrem de e geram interações entre os indivíduos e entre eles e o ambiente em que vivem [...] com o propósito de produzir bens, transmitir valores, significados, ensinar a viver e a controlar o viver" (OLIVEIRA et al, 2014, p. 33).

Ainda no sentido apontado pelos/as autores/as, o conceito de práticas sociais nos remete ao processo dinâmico de constituição de identidades, valores, atitudes e na produção/reprodução de relações de significados, visto que "[...] nelas, as pessoas expõem, com espontaneidade ou restrições, modos de ser, pensar, agir, perceber experiências produzidas na vida, no estudo de problemas e dificuldades, com o propósito de entendê-los e resolvê-los" (OLIVEIRA et al, 2014, p. 35). Assim, as práticas sociais situam-se inexoravelmente no tempoespaço, ou melhor, são elas mesmas constitutivas deste tempo-espaço, pois decorrem de uma construção realizada essencialmente pelos seres humanos, em sua relação histórica e existencial ao mundo (MERLEAU-PONTY, 2006).

Freire $(2006 ; 2011)$ nos propõe um entendimento sobre a história que coloca a práxis humana no centro da elaboração da realidade social objetiva, visto que o processo histórico só pode ser edificado na medida em que os próprios seres humanos lhe atribuem uma significação existencial, fundamentada na implicação mútua e constante entre ação-reflexão, prática-teoria. Parece-nos esta uma razão para Freire afirmar, de um lado, que “[...] a realidade social, objetiva, que não existe por acaso, mas como produto da ação dos homens, também não se transforma por acaso" (p. 51), bem como "[...] não haveria ação humana se não houvesse uma realidade objetiva, um mundo como 'não eu' do homem, capaz de desafiá-lo" (FREIRE, 2011, p. 55).

É no seio das relações intrínsecas e mutuamente constitutivas entre seres humanosmundo que passamos a atribuir sentido às diversas práticas sociais realizadas pelas pessoas, em contextos espaço-temporalmente situados. Tratamos, portanto, de um mundo humano que é conscientemente modificado, significado existencialmente a partir da intencionalidade transformadora, num movimento em que homens e mulheres se constituem e se reconstituem continuamente no que-fazer histórico. Segundo Fiori (2014b), “[...] o significar ativo em que o mundo é significado não se efetua como atividade de uma consciência pura subjetividade. Este significar, ao contrário, é um comportamento corpóreo-mundano e existencial no qual se constitui e reconstitui o mundo significado" (p. 87).

O movimento de retomada reflexiva realizado por parte dos sujeitos da ação, em que consciência e existência se recompõem em sua unidade originária, reintegram igualmente os seres humanos ao seu mundo vivido, pensado, buscado e criado num que-fazer permanente, expressão essencial e constitutiva da práxis: 
A reflexividade é a raiz da objetivação. Se a consciência se distancia do mundo e o objetiva, é porque sua intencionalidade transcendental a faz reflexiva. Desde o primeiro momento de sua constituição, ao objetivar seu mundo originário, já é virtualmente reflexiva. É presença e distância do mundo: a distância é a condição da presença. Ao distanciar-se do mundo, constituindo-se na objetividade, surpreende-se, ela, em sua subjetividade. Nessa linha de entendimento, reflexão e mundo, subjetividade e objetividade não se separam: opõem-se, implicando-se dialeticamente. (FIORI, 2014a, p. 73-74).

Nesta relação permanente que homens e mulheres estabelecem com seu mundo cultural, na manifestação mesma desta práxis histórica, ambos vão permanentemente se constituindo, num movimento ininterrupto em que tanto a ação humana é capaz de transformar a realidade social, quanto também os seres humanos são condicionados pelos efeitos de suas próprias ações no mundo, desde o passado constitutivo do presente, mas também do presente que projeta o futuro. Tal relação manifesta-se existencialmente de forma objetiva, subjetiva e, primordialmente, intersubjetiva.

Deste modo, é no bojo desta relação permanente de constituição recíproca entre seres humanos-mundo que podemos compreender o processo de humanização e a historicização do mundo enquanto processo educativo, visto que a própria concepção de prática social enquanto práxis revela, na dialética estabelecida entre ação-reflexão transformadora, o retomar reflexivo pelos quais as pessoas podem transcender a si mesmas e ao mundo. Para Freire, "[...] aí se encontram as raízes da educação mesma, como manifestação exclusivamente humana. Isto é, na inconclusão dos homens e na consciência que dela têm. Daí que seja a educação um quefazer permanente. Permanente, na razão da inconclusão dos homens e do devenir da realidade" (FREIRE, 2011, p. 101-102).

Este movimento em direção a um devenir da realidade, que parte da condição existencial humana desde um aqui e um agora, de um corpo-aqui e um mundo-aqui, se configura como uma sucessão ininterrupta de horizontes que continuamente vão se atualizando e, assim, objetificando de forma dinâmica as possibilidades de poder-ser dispostas historicamente (como condicionalidades estruturais) aos indivíduos:

A educação, porque se realiza no jogo destes contrários que se dialetizam, é "duração". A educação "dura" na contradição permanência-mudança. Esta é a razão pela qual somente no sentido de "duração" é possível dizer que a educação é permanente. Por isto mesmo, permanência, neste caso, não significa a permanência de valores, mas a permanência do processo educativo, que é o jogo entre a permanência e a mudança culturais. A dialetização referida permanência-mudança -que torna o processo educativo "durável" é a que explica a educação como um quefazer que está sendo e não que é. Daí seu condicionamento histórico-sociológico. A educação que não se transformasse 
ao ritmo da realidade não "duraria", porque não estaria sendo. (FREIRE, 2006, p. 84).

Ainda referendados em Freire (2006), a problematização das condições históricas que condicionam a manifestação das situações reais, concretas, existenciais dos seres humanos, constitui-se como elemento fundamental para a realização dos projetos de existência que expressam seus modos individuais e plurais de ser. Este que-fazer problematizador configurase como uma práxis de ad-miração e re-ad-miração da realidade social, a partir da qual homens e mulheres se abrem para novas possibilidades de compreensão acerca do mundo humano que, dada sua condição cultural, econômica, histórica, religiosa-espiritual, social, política, de gênero, de orientação sexual, e de raça-etnia, também condiciona os modos de vida de seus/uas criadores/as ensimesmados em dado contexto de mundo.

Neste sentido, compreendemos que as ações humanas transformam não somente ao mundo, mas aos próprios seres humanos e também as instituições nas quais se fazem presentes, a partir da reflexão que realizam em relação à realidade-mundo em que se presentificam, confrontando o domínio da existência humana a partir da dialética entre condicionamento e liberdade (LEOPOLDO E SILVA, 2008). Como nada pode determinar inextricavelmente a vida de homens e mulheres e seus respectivos projetos existenciais, a educação não pode deixar de se constituir como processo permanente, envolvendo intersubjetividade e interconhecimento.

\section{Método fenomenológico e pesquisa em educação}

Enquanto fenômeno ontológico, o processo de educação humana pode ser compreendido a partir de duas dimensões distintas e mutuamente constitutivas de suas formas de manifestação: uma relativa à formação anímica dos indivíduos, a qual se relaciona com a experiência humana de significação do mundo cultural e de constituição de suas identidades individuais/ coletivas; outra representada pelo sentido e direção objetivos assumidos pelos processos sociais e que constituem historicamente uma realidade objetiva comum. Se a primeira dimensão se refere, para utilizar a definição de Larrosa-Bondía, ao saber da experiência, “(...) um saber que revela ao homem concreto e singular, entendido individual ou coletivamente, o sentido ou o sem-sentido de sua própria existência, de sua própria finitude" (LARROSABONDÍA, 2002, p. 27), pela segunda tomaremos o processo manifestado na tensão existente entre os níveis subjetivo e intersubjetivo, do qual resultam as condições históricas que mediatizam as relações sociais. Como as significações sociais podem ser compreendidas de diferentes modos pelos indivíduos, a partir das relações intersubjetivas que permeiam tal 
entendimento, o ato de se educar se configura como próprio a cada pessoa, ainda que seja um processo de criação tão individual quanto social.

Assim sendo, buscamos na fala e no discurso proferido pelos agricultores/ as assentados/as, nas significações atribuídas por eles/as às próprias trajetórias de vida, situadas em contextos espaço-temporais específicos, o elemento central de desvelamento do fenômeno de regresso à terra de trabalho por meio da luta pela reforma agrária (no tocante aos processos educativos constitutivos desta práxis, mas também dos processos sociais mais amplos que a condicionam e que por ela foram condicionados). Para tanto, optamos pelo método fenomenológico de pesquisa, pois partimos do princípio que os "[...] dados obtidos são as situações vividas que foram conscientemente tematizadas pelo sujeito", pois ele "[...] é tido como um atribuidor de significados e não como um mero repetidor de ideias mecanicamente adquiridas" (MARTINS; BICUDO, 1989, p. 94).

Nosso foco analítico voltou-se para a compreensão das experiências de luta pela terra vivenciadas historicamente por agricultores/as residentes no "Projeto de Desenvolvimento Sustentável (PDS) Santa Helena", assentamento implementado no município de São Carlos/SP em 2005 sob a responsabilidade do Instituto Nacional de Colonização e Reforma Agrária (INCRA), o qual viabilizou a cessão de uso de lotes com aproximadamente 5,4 hectares à 14 famílias de agricultores/as. Entre os meses de junho e julho de 2017, após dois anos de convívio com os/as trabalhadores/as assentados/as e de aproximação gradativa com a realidade do assentamento, realizamos entrevistas individuais semiestruturadas com uma pessoa de cada propriedade familiar de produção orgânica do assentamento ${ }^{1}$.

Para análise das descrições obtidas acerca do referido tema, bem como sua posterior formulação na forma de compreensões significativas sobre a estrutura do fenômeno estudado, percorremos dois momentos distintos e conjugados da análise fenomenológica, o ideográfico e o nomotético, realizando o reagrupamento de constitutivos relevantes do fenômeno interpretado a partir da depuração, proporcionada pelas leituras das entrevistas, de categorias gerais relevantes. Tal exercício foi realizado por meio do levantamento e interpretação das unidades de significado identificadas nas descrições de campo (análise ideográfica) e do reconhecimento de seus aspectos convergentes e divergentes (análise nomotética), possibilitando o desvelamento de uma perspectiva do fenômeno (GARNICA, 1997; MARTINS; BICUDO, 1989).

\footnotetext{
${ }^{1}$ Os resultados aqui apresentados foram obtidos por meio de pesquisa de doutorado realizada no Programa de PósGraduação em Educação da Universidade Federal de São Carlos (PPGE/ UFSCar), e contou com o financiamento da Coordenação de Aperfeiçoamento de Pessoal de Nível Superior (CAPES). A pesquisa foi devidamente aprovada pelo Comitê de Ética em Pesquisa em Seres Humanos da UFSCar.
} 


\section{Gente que veio da terra}

O processo de modernização agrícola no Brasil provocou profundas transformações no tocante às formas possíveis de acesso à terra pelos pequenos produtores rurais, afetando, consequentemente, os modos plausíveis de realização do trabalho no campo e por conseguinte as possibilidades de reprodução social das famílias rurícolas. Entretanto, a princípio, o desenvolvimento capitalista da agricultura no Brasil se deu a partir da existência de uma fronteira agrícola que se movimentou constantemente de acordo com a disponibilidade de terras ainda não apropriadas legalmente. Tal processo, ao mesmo tempo em que propiciou uma renda diferencial crescente aos grandes proprietários rurais (dadas as diminuições dos custos de produção decorrentes do saldo entre a fertilidade natural e a localização dos solos), também garantiu a reprodução dos pequenos posseiros, parceiros e arrendatários, ainda que muitas vezes de maneira subordinada ao processo de sustentação do monopólio da propriedade fundiária e de captação de renda da terra, dada as formas precária de acesso à ela disponíveis (GRAZIANO DA SILVA, 1980).

O conjunto de agricultores e agricultoras assentados/as no PDS Santa Helena nasceu no Brasil entre os anos de 1943 e 1971, sendo naturais dos estados da Bahia, Paraná e Minas Gerais. Em comum nas suas trajetórias de vida, a origem da vida no campo, o trabalho na roça quando criança, a partida de sua terra natal, as constantes migrações, o ingresso na luta pela terra, o regresso à terra de trabalho. Em uma perspectiva histórica, aprender a vida da roça implicou, a estes sujeitos, a constituição e a formulação de uma percepção integrada desta vivência na infância, onde os processos educativos foram se erigindo de modo atrelado: 1) às possibilidades concretas de acesso à posse da terra e ao estabelecimento de suas famílias no campo, condição fundamental para instituição da terra de trabalho; 2) à forma de reprodução familiar proporcionada pelo trabalho produtivo visando o autoconsumo; 3 ) à valoração positiva do trabalho na terra do qual tiravam seu sustento, advindo, disso, o gosto e o prazer pelo trabalho aprendido.

Sob um primeiro aspecto, $\mathrm{o}$ ato de aprender a vida da roça foi forjado pelas experiências vivenciadas a partir de certas condições de vida na roça. Foi no seio de cada realidade históricosocial situada que foram se erigindo os processos educativos decorrentes das práticas sociais vivenciadas na infância no meio rural, processos que se apresentaram fundamentalmente a partir da possibilidade de transmissão de conhecimento geracional proporcionado pela forma com que se estruturava e organizava o trabalho familiar no manejo produtivo da terra: "Meu pai seguia na frente com a enxada e nós atrás com a enxadinha. Com seis anos, todos nós 
tínhamos as enxadinhas. Todos" (Informação Verbal - Entrevista VII) ${ }^{2}$. Conforme sugere a fala citada, o arranjo do trabalho efetivado no meio rural em meados da década de 1960 envolvia, em muitos casos, a participação de pais, mães, filhos, filhas e demais integrantes da família, ainda que conformado a partir de uma divisão sexual e etária condicionante do tipo de atividade passível de ser realizada por cada um dos integrantes do arranjo.

Viver na roça vivendo da roça foi uma condição experienciada fundamentalmente por aqueles que conseguiram estabelecer uma relação de maior estabilidade no usufruto da terra na virada da primeira para segunda metade do século $\mathrm{XX}$, a qual gerava o sustento ancorado na estrutura familiar como base da vida econômica. Possibilitou, em muitos casos, a construção de uma relação de autonomia com o trabalho na terra a partir de sua posse, traduzida na diferenciação entre o trabalhar para si mesmo e trabalhar para um patrão, e, portanto, na possibilidade da utilização da propriedade rural como terra de trabalho:

Eu toda vida fui curiosa, desde pequenininha. Aí minha mãe ia para o meio do mato. Era uma matão assim. O monjolo era lá no matão, no fundo. Ela falava: Hoje vou pegar milho e socar farinha”. Descia aquela mata a fora. Eu chorava que queria ir com ela, ela me levava. Aí ela acendia o fogo ali. Ali em volta era tudo limpinho. E ali ela ia socando a farinha. Ali, aquele fubá... Saía um fubá! Ali ela coava na peneirinha fina e ali já ia passando no tachão e fazendo a farinha de milho. Fazia um saco assim de farinha de milho. Aí, de manhã, nossa comida era farinha de milho com leite. Paçoca de carne com farinha socada. De porco. O pai matava o porco e punha tudo salgado, bem salgado pra conservar. Aí punha no pilão a carne e a farinha e socava. Era nossa comida. Era nosso café da manhã. Era paçoca de carne ou leite com farinha. Com aquela farinha tirava cada biju! Aquela farinha, nossa! [...] E minha mãe fazia assim. E eu ia até junto da minha mãe pra ver como ela fazia. Aí matava o porco. Eu e minha irmã mais velha. Elas mais velhas. Aí minha mãe matava o porco. Ela matava o porco, eu era pequenininha. Mas eu ia junto com ela pra aprender como matava, como cortava a carne, como tirava. Aí tirava toda carne para um canto, o toicinho para o outro. Era tudo porcão grande. [...] Mas era muita fartura. Muita fartura mesmo. Falar que passamos fome naquele lugar, não passamos. Era muita fartura. Tinha galo, muito animal. Muita fartura. Tinha muito de todas as coisas. Nossa, era uma festa pra gente! (Informação Verbal - Entrevista I) ${ }^{3}$.

As atividades laborais voltadas para o autoconsumo, as quais engendravam a possibilidade de tirar da própria terra o sustento da família, atrelada à baixa necessidade da aquisição monetária para a reprodução da vida no campo, ainda sim suprida pelo próprio trabalho na terra, nos remetem a um modo de manifestação das relações econômicas cuja centralidade se encontra no processo de transformação da natureza por meio do trabalho

\footnotetext{
${ }^{2}$ Entrevista concedida por Silva, Maria Aparecida Rosa. Entrevista VII [jul. 2017]. Entrevistador: D. M. T. São Carlos, 2017. 1 arquivo .mp3 (70 min.).

${ }^{3}$ Entrevista concedida por Ribeiro, Lindamira Aparecida Teodoro. Entrevista I [jun. 2017]. Entrevistador: D. M.

T. São Carlos, 2017. 1 arquivo .mp3 (65 min.).
} 
humano, realizado intersubjetivamente a partir de um arranjo familiar dos afazeres cotidianos de produção e reprodução da vida que busca, essencialmente, garantir a satisfação material de seus pares. Se, por um lado, esta experiência engendrou, nos/as adultos/as que foram forjados em tais condições de infância, aprendizados relativos ao modo com que se dividiam as responsabilidades das tarefas cotidianas com base em critérios de gênero e idade, gerou igualmente a valorização da vida e do trabalho na terra, bem como enaltecimento dos muitos aprendizados proporcionados pela rica e diversa vivência familiar.

Esta estrutura formal da vida econômica no campo, baseada mais na relação de consumo daquilo que se pode produzir por meio do trabalho em detrimento àquilo que se pode comprar a partir da produção especializada de bens/serviços comercializáveis, engendrou uma diversidade de tratos, manejos e atividades no cotidiano de reprodução familiar manifestada pela variedade de saberes e habilidades que as pessoas no meio rural detinham neste período histórico. Por conseguinte, condicionou as possibilidades de aprendizado das crianças inseridas na estrutura familiar de organização do trabalho, refletidas na qualidade dos processos educativos proporcionados pela ação doméstica de se matar um porco para retirar sua carne e sua banha, ou de se plantar, colher e moer o trigo para fazer a farinha que possibilitará o pão farto e a alegria na mesa do café da manhã ou da tarde, em comparação à subjetivação gerada a partir da satisfação material viabilizada pela aquisição de bens de consumo em um mercado marcado por relações impessoais monetizadas.

Aprender a vida da roça significou, destarte, a construção de uma memória afetiva ligada à ideia de alegria, festa, prazer, sossego, vida boa e tranquilidade àqueles que gozavam daquilo que a terra trabalhada então proporcionava. Em nossa compreensão, tal significação não se encontra relacionada tão somente com a experiência infantil de roça tomada em si mesma, mas parte igualmente de uma valorização ressignificada em função de todo o caminho percorrido entre a saída do campo até o momento do regresso à terra de trabalho, concretizado por meio da participação na luta dos movimentos sociais campesinos. Isto se deveu, conforme pudemos ir percebendo ao longo das entrevistas com agricultores e agricultoras, em aprendizados relacionados ao enaltecimento da importância do trabalho agrícola para a reprodução social das famílias e ao amor pelo sustento direto tirado do trabalho na terra, aprendizados que permaneceram gravados indelevelmente em suas visões de mundo e que nos ajudam a compreender a condição atual de assentados.

Estas experiências e lembranças da infância, encarnadas nas suas formas de ser no presente, percorreriam o transcurso de suas trajetórias de vida, associando-se, não sem tensão, com o movimento histórico de urbanização e financeirização das condições de reprodução 
social experimentado especialmente a partir da década de 1950, com a intensifícação do processo de modernização capitalista brasileiro. Deste modo, o retorno à roça representaria, tempos depois, a possibilidade destes/as homens e mulheres voltarem a expressar seus gostos e saberes adquiridos ou, simplesmente, a expressarem o gosto pelo saber que se sabe: "Eu sempre gostei da terra. Fui criado na terra. Na cidade, com um pedacinho de terra, você não consegue fazer nada. E no terreno que eu tinha plantava milho, feijão, abóbora. Aí peguei, viemos pra cá. Eu gosto da terra" (Informação Verbal - Entrevista III) ${ }^{4}$.

\section{Da terra à lona}

Como era um lugar pequeno, cidade pequena, não tinha muitos recursos na área urbana, na cidade. Então, a gente já fez como a ideia de vir embora pra cidade grande. Aí meus pais sentiram muito, minha mãe mesmo. Eu fui o último a sair de casa. Meus irmãos todos já tinham vindo. Aí um foi convidando o outro e foi vindo um por um. Acabou vindo quase todo mundo pra cá. Teve um irmão meu que veio pra cá, depois voltou pra lá, está com eles pra lá. Porque, na cidade, se você não tem uns cursos, não tem um estudo melhor, a gente não consegue muita coisa não. Fica pior do que morar com eles lá no sítio. Fica bem mais dificultoso. Você consegue arrumar serviço, mas serviço bruto, serviço pesado, então se tornaria quase a mesma coisa. Ganhando pouco. A gente faz as coisas pensando em cada vez melhorar mais. A minha mãe falava assim: "Não vai lá, você vai encontrar dificuldade". Todo lugar é difícil. Mas uma hora ou outra a gente tem que sair pra procurar uma melhora. Eu trabalhei um bom tempo na cidade (Informação Verbal - Entrevista II) ${ }^{5}$.

As tendências que se delinearam, desde a década de 1950, nas atividades agrícolas a nível regional, como consequência do processo de capitalização e mecanização pela qual passou a agricultura brasileira, reforçaram a tendência geral no campo em relação à manutenção e ao incremento das grandes empresas e propriedades rurais e ao aumento do volume de trabalhadores/as temporários/as utilizados/as para os serviços agrícolas. Consideradas as profundas alterações da estrutura e da composição da força de trabalho do campo resultantes da intensificação do uso de máquinas/ insumos industriais e da substituição das culturas permanentes pelas temporárias e pastagens, aspectos que por sua vez contribuíram para o agravamento do quadro de elevada concentração fundiária no Brasil, o fenômeno do êxodo rural pôde se manifestar de modo particularmente intenso a partir da década de 1960, afetando diretamente a vida das pessoas até então residentes no meio rural brasileiro (MARTINE, 1991).

\footnotetext{
${ }^{4}$ Entrevista concedida por Azevedo, Sebastião Alves. Entrevista III [jul. 2017]. Entrevistador: D. M. T. São Carlos, 2017. 1 arquivo .mp3 (23 min.).

${ }^{5}$ Entrevista concedida por Oliveira, José Maria de Souza. Entrevista II [jul. 2017]. Entrevistador: D. M. T. São Carlos, 2017. 1 arquivo .mp3 (72 min.).
} 
Por um lado, a recorrência à migração para lidar com a constante necessidade de movimentar-se pelo mundo por uma vida melhor designou um imaginário subjetivo e intersubjetivo construído em relação à atração exercida pelo estilo de vida caracteristicamente cosmopolita dos agrupamentos humanos urbanizados. Também pela maior probabilidade de obtenção de trabalho digno e de renda justa e segura, ainda que tal consecução estivesse mediada pela impossibilidade de acesso histórico-geracional das famílias de agricultores/as à escolarização formal: "Eu nunca estudei, ele também não. [...] Se eu tivesse estudo, estaria bem" (Informação Verbal - Entrevista VIII) ${ }^{6}$, nos disse uma das agricultoras, ao buscar compreender em sua reflexão o porquê dela e de seu marido não terem conseguido se estabelecer no mercado de trabalho paulista.

Tal condição retrata uma época de extrema dificuldade de acesso da população vivente no campo ou originária dele ao ensino regular, oriunda da diminuta oferta pública de tal serviço no meio rural, das precárias condições de infraestrutura e mobilidade nestas regiões, e também das condições objetivas da realidade social brasileira, que impelia a um esforço conjunto dos membros das famílias migrantes em busca do seu sustento, o que inviabilizava a opção do estudo de filhos e filhas. Considerando a importância fundamental da obtenção de renda financeira para manutenção das famílias trabalhadoras, dada a radicalização experimentada à época pelos centros urbanos consolidados em relação à monetarização das formas de reprodução da vida social (e, portanto, à satisfação das necessidades materiais cada vez mais mediadas pela produção industrial), a busca por qualificação técnica apareceu a um conjunto de agricultores/as como ação alternativa visando o ingresso no mercado de trabalho no interior e na capital do estado de São Paulo, dado suas histórias pregressas de dedicação ininterrupta aos serviços relacionados ao manejo agrícola e de precário acesso a educação escolar, entendida até então como estratégia privilegiada por quase todas as famílias para proporcionar melhores condições de vida para os mais jovens.

$\mathrm{Na}$ maioria dos casos analisados, as condições objetivas de vida e trabalho coincidiram com aquelas dispostas no processo de constituição e consolidação de bairros urbanos periféricos ${ }^{7}$ e empobrecidos em grandes e médias cidades brasileiras, marcadas pela volatilidade das relações econômicas e sociais próprias à forma subordinada e controlada com que os migrantes puderam se inserir na dinâmica social e nos espaços centrais de produção e

\footnotetext{
${ }^{6}$ Entrevista concedida por Almeida, Honorina Nascimento; Almeida, Claudio Francisco. Entrevista VIII [jul. 2017]. Entrevistador: D. M. T. São Carlos, 2017. 1 arquivo .mp3 (128 min.).

${ }^{7}$ Tratamos as periferias como realidade complexa cuja produção cotidiana da vida é constituída por dinâmicas sociais que conectam tais espaços, de forma controlada e subordinada, às dinâmicas que integram o 'centro' da vida urbana. Ver: Telles (2001); Feltran (2010; 2011); Georges; Silva (2008); Rizek; Georges (2008); Scirè (2009; 2010); Almeida; D' Andrea; De Lucca (2008) e Rosa (2008; 2009).
} 
reprodução da vida citadina, especialmente aquelas relacionadas à: 1) instrumentalização e funcionalização do trabalho realizada a partir da correspondência entre a necessidade proeminente de geração de renda e a existência de processos de acumulação privada e de exploração de mão de obra; 2) à qualidade dos vínculos sociais estabelecidos no interior dos circuitos de reciprocidade (família, vizinhança, redes de assistência) e à sua importância enquanto fator de proteção ou de limitação à mobilidade social.

Dito isto, os aprendizados relacionados ao contraponto existente entre as formas de reprodução social das famílias possíveis no meio rural e urbano manifestaram-se, nas trajetórias consideradas, especialmente pelo modo como os/as agricultores/as puderam significar a distinção material e simbólica das diferentes qualidades do produto dos trabalhos gerados pelo desempenhado de atividades produtivas nestes dois lócus de vida. No campo, a possibilidade de estabelecimento (ainda quando instável) de uma relação mais perene com a terra enquanto local de moradia e trabalho (seja pela posse ou por contratos de parceria e arrendamento) permitiu às famílias a realização dos plantios de subsistência da chamada lavoura branca ${ }^{8}$, instituindo um aprendizado acerca do valor positivo da viabilidade de obtenção desta forma de sustento direto. $\mathrm{Na}$ cidade, onde mais intensamente se manifestaram as relações econômicas monetizadas, a dificuldade de estabelecimento das famílias no mercado de trabalho urbano e rural (configuradas de acordo com cada contexto econômico regional, mas também pelas possibilidades de constituição prévia de redes de solidariedade pautada por laços pessoais e pelo nível de qualificação técnica e escolarização dos sujeitos) resultou, na maior parte dos casos, em condições de vida instáveis relacionadas à precária qualidade dos empregos obtidos ao longo dos movimentos migratórios.

Convivendo com a permanente intermitência das condições e possibilidades de reprodução social de suas famílias, expressas pelas inúmeras mudanças realizadas em busca de serviço em municípios diversos, os/as agricultores/as aprenderam a conviver com outro tipo de relação envolvendo a temporalidade do trabalho e da vida citadina, contrastando-a com a temporalidade bem marcada aprendida durante as trajetórias construídas desde a infância (expressa por meio da cadência do trabalho no campo ritmada pelo movimento solar), percebendo a distinção entre os ritmos da vida cotidiana num e noutro lugar e valorizando aquilo que um dia havia vivido na roça.

Mas tudo pra gente era novo. Não eram coisas que estávamos acostumados a fazer. Deu uma mudada brusca na vida. Falando de serviço. Trabalhava a noite.

\footnotetext{
${ }^{8}$ Lavoura branca: lavoura que não é perene, precisa ser plantada todos os anos. Exemplo: milho, algodão, arroz etc.
} 
Coisa que no sítio é diferente. Tinha o horarinho. Deu aquele horário, vai pra roça. Tudo é no horário. Tudo é no tempo. Deu aquele horário, vai almoçar. Deu aquele horário, vai tomar café. Na cidade, não. Na cidade não tem hora pra comer, não tem hora pra dormir, não tem hora pra nada. É uma correria danada. Por isso, quando me falaram que a gente poderia conseguir umas terras, eu não pensei duas vezes. Vim pra ver se conseguia as terras (Informação Verbal Entrevista II).

No esteio das possibilidades de viração existentes no mercado formal e informal de trabalho, com as quais os sujeitos jogavam a fim de obter alguma forma de proteção em relação ao (incerto) futuro, ter uma vida melhor pôde designar a esperança descrente de encontrar-se em algum lugar do mundo, dada a concretização da inviabilidade da permanência em sua terra natal. Pôde denotar, ainda, uma esperança manifesta no desejo de saída, motivado pelo inconformismo com as condições de vida momentâneas e pela expectativa aventada com as possibilidades abertas pelas incertezas dos caminhos desconhecidos, advindas da incompletude constitutiva do percurso histórico.

Enfim, o decurso das trajetórias consideradas exigiu uma constante necessidade de aprender a se adaptar às constantes mudanças exigidas em relação ao modo de realização de suas vidas cotidianas, frente às formas de reprodução social dispostas em cada contexto situado. Destarte, manifestando o gosto pela terra e a valorização da possibilidade de sustento direto que a vida no meio rural lhe possibilitara na infância, em comparação às formas monetizadas de consumo posteriormente vivenciadas nos aglomerados urbanos, tais trabalhadores/as puderam direcionar suas decisões de vida, dentre as escolhas historicamente disponíveis, rumo ao ingresso em movimentos sociais de luta pela terra ${ }^{9}$.

Ao evidenciarmos os processos educativos vivenciados pelos/as agricultores e agricultoras entre o nascimento no meio rural e o ingresso em tais movimentos, enfatizamos a importância que as experiências de vida na roça tiveram na construção das identidades próprias dos sujeitos e também na conformação da intencionalidade de suas ações com o mundo. Entretanto, tal compreensão fortalece igualmente nossa percepção em relação à possibilidade da existência de uma ruptura geracional no processo de sucessão dos assentamentos de reforma agrária, proporcionada pela natureza evidentemente distinta das experiências vivenciadas por seus filhos e filhas nascidos no transcorrer dos vários movimentos migratórios ou na periferia empobrecida de um centro urbano.

Se minha família, pelo menos meus filhos, se eles não pegarem esse amor pela

\footnotetext{
${ }^{9}$ De acordo com Fernandes, “[...] a intensificação das ocupações de terra causou grande impacto político, de modo que os sem-terra passaram a ser os principais interlocutores, no enfrentamento com o Estado, na luta pela terra e pela reforma agrária" (FERNANDES, 2001, p. 07).
} 
terra, explicando quais são as dificuldades e quais são as coisas que a terra dá pra gente, vai chegar uma época que eles não terão a mesma ideia da gente. Vão acabar desanimando, abandonado a terra e cometendo o mesmo erro que a gente fez. A gente fez por dificuldade e eles vão acabar fazendo por opção. Minhas filhas são todas mulheres. [...] Então, eu falo pra elas: "Porque você vai sair daqui pra ir pra cidade? Vai procurar o que lá? Se a maior riqueza nossa é o bem estar da gente, a saúde da gente". Você é saudável, come do melhor. Está sabendo o que você está comendo porque é você quem está produzindo. [...] Se acontecer de elas abandonarem a terra, não vou poder fazer nada. Mas nós aprendemos que as dificuldades na cidade são bem maiores que na roça, na terra. Por isso que eu vim de novo pra terra. Porque aqui, faltou alguma coisa, você sai ali e arruma. Na cidade não, se faltou na cidade, se você não tem dentro da sua casa, saiu na rua você tem que arrumar. Tem que se virar pra ter o que comer. Aqui, principalmente, pra comer, você sai ali na horta, pega alguma coisa. Faltou mistura, pega uma galinha caipira e mata. Pra mim, eu estou no céu. Não preciso nem morrer (Informação Verbal - Entrevista II).

A valorização da vida na terra promovida pelos/as assentados/as está ligada, conforme indicam nossos dados de campo, à possibilidade de realização de um trabalho que gera o alimento saudável para si e para os outros, mas também ao prazer e satisfação com que desempenham o próprio processo laboral agrícola, aprendido desde as infâncias vivenciadas com seus familiares na roça; tais sujeitos aprenderam, igualmente, a relativizar a importância do dinheiro em suas vidas sem negar-lhe sua função fundamental para a reprodução social da vida familiar na atualidade, significando o viver bem da terra enquanto viver com pouco e com riqueza de saúde, condição proporcionada pelo amor com que cumprem o trabalho do campo e com a garantia mínima de subsistência que ele propiciará. Se, como nos disse um dos entrevistados, no campo tudo é no tempo, foi na luta pela terra que esta geração de agricultores/as vislumbraria reencontrar a forma, jamais conclusiva, de se encontrar no tempo do mundo.

\section{Considerações}

Partindo do entendimento de que “[...] a realidade contraditória vivenciada pelas famílias assentadas nos leva a associar sua investigação ao processo histórico de constituição do campesinato brasileiro" (DUVAL; FERRANTE; BERGAMASCO, 2015, p. 76), buscamos neste artigo compreender os movimentos passados de ingresso e participação de agricultores/as viventes em um assentamento rural paulista em processos de luta pela terra. Tomamos tal ação enquanto expressão da educação forjada até o momento de vida em que puderam manifestar a intenção do regresso ao campo por meio de tal prática, argumentando que os processos educativos forjados neste percurso referiram-se às distintas formas de conscientização do contraditório vivenciadas no decorrer de suas experiências de roça e de cidade. Considerando 
os aspectos comuns no tocante às relações de propriedade e de acesso à terra estabelecida por suas famílias nucleares ou extensas nas regiões em que construíram suas estratégias de reprodução social (sem com isso ofuscar as particularidades e a intencionalidade de cada movimento individual ou familiar advindo da retomada reflexiva do mundo vivido realizado por parte de cada sujeito da ação), situamos o momento inicial das trajetórias de vida destes/as agricultores/as através da raiz campesina que se constituiu enquanto matriz das distintas experiências focalizadas, as quais embrincaram-se com o contexto agrário brasileiro e culminaram com suas participações em movimentos de trabalhadores sem-terra.

Não queremos sugerir, com isso, que estes pontos de partida análogos das trajetórias de vida dos sujeitos tenha definido, a priori, o ponto de chegada indicado. Primeiramente, porque o intervalo de 30 anos decorridos entre 1940 e 1980, dentro do qual se desenrolaram suas infâncias na roça, representou um período histórico de intensas transformações nas dinâmicas sociais brasileiras decorrentes do processo de industrialização e modernização capitalista que se acentuou no país, o que condicionou de modo diverso, nas diferentes localidades, as condições objetivas de reprodução social das famílias. Além disso, também foi diversa a forma com que cada uma dessas famílias e de seus/uas integrantes significou e encaminhou sua própria trajetória em relação às possibilidades e expectativas do porvir, dispostas a partir de suas distintas realidades sociais.

Os processos educativos revelados a partir da análise dos movimentos dinâmicos e contingenciais de lutas e resistências presentes nas trajetórias dos/as agricultores/as e nos discursos proferidos por eles/as acerca deste tempo passado, em narrativas construídas em relação à integralidade histórica das distintas trajetórias de vida, expressam o equilíbrio instável existente entre as dimensões subjetiva e objetiva de suas respectivas existências. É deste movimento de construção da intencionalidade da ação proporcionada pela singularização reflexiva dos sujeitos, gerada por sua vez pelos processos educativos decorrentes de cada experiência analisada, que nos aproximamos quando situamos tais processos em relação aos conflitos, contradições e dilemas de vida vivenciados no decorrer de suas experiências de roça e de cidade. Revelam, em nossa compreensão, as distintas formas de conscientização do contraditório inerentes à constituição dos processos de aprendizado que engendraram suas ações passadas e que significam sua condição presente.

\section{REFERÊNCIAS}

ALMEIDA, R.; D'ANDREA, T.; DE LUCCA, D. Situações periféricas: etnografia comparada de pobrezas urbanas. Novos Estudos CEBRAP (82), p. 109-130, 2008. 
CARVAlHO, J. G. Questão Agrária e Assentamentos Rurais no Estado de São Paulo: o caso da Região Administrativa de Ribeirão Preto. Tese (Doutorado) - Universidade Estadual de Campinas, Campinas, 2011.

DELGADO, G. C. Capital financeiro e agricultura no desenvolvimento recente da economia brasileira. Tese (Doutorado) -- Universidade Estadual de Campinas, Campinas, 1984.

Do capital financeiro na agricultura à economia do agronegócio: mudanças cíclicas em meio século [1965-2012]. Porto Alegre/RS: Editora UFRGS, 2012.

DUVAL, H.C.; FERRANTE, V. L. S. B.; BERGAMASCO, S. M. P. P.. Sobre o uso da teoria do campesinato na contemporaneidade. Raízes (UFPB), v. 35, p. 62-78-78, 2016.

FELTRAN, G. Periferias, direito e diferença: notas de uma etnografia urbana. Revista de Antropologia. n. 53, v.2, Universidade de São Paulo, p. 565-610, 2010.

Fronteiras de tensão: um estudo sobre política e violência nas periferias de São Paulo. São Paulo/SP: Editora UNESP, 2011.

FERNANDES, B. M. A ocupação como forma de acesso à terra. In: ENCONTRO DE GEÓGRAFOS DA AMÉRICA LATINA, 08, 2001, Santiago de Chile. Anais... Santiago de Chile, Universidad de Chile, 2001.

FERRANTE, V. L. S. B.; BARONE, L. A.; DUVAL, H. C. O final de um ciclo? Reflexões sobre assentamentos rurais no Estado de São Paulo. REDD - Revista Espaço de Diálogo e Desconexão, v. 5, n. 1, p. 01-28, 2012.

FIORI, E. M Educação Libertadora. In: Política. Porto Alegre/RS: L\&PM, 1991, p. 83-95.

Textos escolhidos, Vol. II, Educação e

Aprender a dizer a sua palavra. In: E. M. FIORI. Educação e Política: textos escolhidos - volume II. 2a ed. Porto Alegre/RS: Editora da UFRGS, 2014a, p. 67-81.

. Conscientização e educação. In: E. M. FIORI. Educação e Política: textos escolhidos - volume II. 2a ed. Porto Alegre/RS: Editora da UFRGS, 2014b, p. 83-104.

FREIRE, P. Extensão ou comunicação? 13 ed. Rio de Janeiro/RJ: Paz e Terra, 2006. Pedagogia do oprimido. 50 ed. Rio de Janeiro/RJ, Paz e Terra, 2011.

GARNICA, A. V. M. S. Algumas notas sobre pesquisa qualitativa e fenomenologia. Interface - Comunicação, Saúde, Educação, v.1, n.1, p. 109-122, 1997.

GEORGES, I.; RIZEK, C. A periferia dos direitos. In: 32. ENCONTRO NACIONAL DA ANPOCS, 32., 2008, Caxambu/MG. Anais... São Paulo: ANPOCS, 2008. p. 02-22.

GEORGES, I.; SILVA, C. F. A naturalização da precariedade: trabalho informal, autônomo e cooperativado entre costureiras em São Paulo (Brasil). Revista Latinoamericana de Estudios del Trabajo, p. 79-95, 2008. 
GRAZIANO DA SILVA, J.. Progresso técnico e relações de trabalho na agricultura paulista. Tese (Doutorado) - Universidade Estadual de Campinas, Campinas, 1980.

LARROSA-BONDÍA, J. Notas sobre a experiência e o saber da experiência. Revista Brasileira de Educação, Rio de Janeiro, n. 19, p. 20-28, 2002.

LEOPOLDO E SILVA, F. Descontrole do tempo histórico e banalização da experiência. In: NOVAES, A. (Org.) Mutações: ensaios sobre as novas configurações do mundo. São Paulo: SESC - Agir, 2008, p. 149-162.

MARTINE, G.. A trajetória da modernização agrícola: a quem beneficia? Lua Nova, São Paulo, n. 23, p. 07-37, 1991.

MARTINS, J.; BICUDO, M. A. da V. A pesquisa qualitativa em psicologia, fundamentos e recursos básicos. 2. ed. São Paulo/SP: Moraes EDUC, 1989.

MERLEAU-PONTY, M. Fenomenologia da Percepção. $3^{\text {a }}$ ed. São Paulo/SP: Martins Fontes, 2006.

MIRANDA, E. L.; FIUZA, A. L. C. Movimentos Sociais Rurais no Brasil: o estado da arte. Rev. Econ. Sociol. Rural, Brasília, v. 55, n. 1, p. 123-136, Jan. 2017.

OLIVEIRA, M. W. de. Et al. Processos educativos em práticas sociais: reflexões teóricas e metodológicas sobre pesquisas em espaços sociais. In: OLIVEIRA, M. W. de; SOUSA, F. R. (Org.). Processos educativos em práticas sociais: pesquisas em educação. São Carlos, SP: EdUFSCar, 2014, p. 29-46.

ROSA, T. T. Fronteiras em disputa na produção do espaço urbano: a trajetória do "Gonzaga" de favela a bairro de periferia. Dissertação (Mestrado). Instituto Filosofia e Ciências Humanas, Universidade Estadual de Campinas, Campinas, 2008.

. Favelas, Periferias: uma reflexão sobre conceitos e dicotomias. In: ENCONTRO ANUAL DA ANPOCS, 33., 2009, Caxambu /MG. Anais... São Paulo, ANPOCS, 2009.

SEVERINO, A. J. Educação, sujeito e história. São Paulo: Olho d'água, 2001.

SCIRÉ, C. D. de O. Consumo popular, fluxos globais: práticas, articulações e artefatos na interface entre a riqueza e a pobreza. Dissertação (Mestrado). Faculdade de Filosofia, Letras e Ciências Humanas, Universidade de São Paulo, São Paulo, 2009.

. Financeirização da pobreza: crédito e endividamento no âmbito das práticas populares de consumo. Teoria \& Pesquisa, v. 20, p. 65-78, 2011.

SOUZA, M. A. de. Pesquisa educacional sobre MST e educação do campo no Brasil. Educ. rev., Belo Horizonte, v. 36, 2020.

TELLES, V. da S. Pobreza e Cidadania. São Paulo: Editora 34, 2001. 


\section{SOBRE O AUTOR:}

\section{Diogo Marques Tafuri}

Doutor em Educação pela Universidade Federal de São Carlos (2019). Integra o quadro de pesquisadores do Núcleo Multidisciplinar Integrado de Estudos, Formação e Intervenção em Economia Solidária da Universidade Federal de São Carlos (NUMI-ECOSOL/ UFSCar) e da Cooperativa de Trabalho e Assessoria Técnica, Extensão Rural e Meio Ambiente (AMATER). E-mail: diogotafuri@gmail.com (iD https://orcid.org/0000-0003-0880-1243 